\title{
Colitis por citomegalovirus: una causa de hemorragia digestiva baja masiva
}

\author{
Cytomegalovirus colitis: a cause of severe lower gastrointestinal bleeding
}

Yurena Caballero-Díaz ${ }^{*}$, Dácil Montesdeoca-Cabrera, Borja Camacho-Fernández-Pacheco, Macarena Centeno-Haro ${ }^{2}$ y Juan R. Hernández-Hernández ${ }^{1}$

${ }^{1}$ Servicio de Cirugía General y del Aparato Digestivo; '2Servicio de Anatomía Patológica. Complejo Hospitalario Universitario Insular Materno-Infantil de Gran Canaria, Las Palmas, España

\begin{abstract}
Resumen
La infección por citomegalovirus es poco frecuente, afecta sobre todo a sujetos inmunocomprometidos y los pacientes de este grupo tienen una alta morbilidad y mortalidad. La clínica de la reactivación o reinfección del virus puede variar desde formas asintomáticas hasta complicaciones graves específicas de órgano, como la hemorragia del tracto gastrointestinal masiva. Es de vital importancia un tratamiento adecuado con antivirales; la opción quirúrgica se reserva para las complicaciones gastrointestinales de acuerdo con la situación clínica del paciente. Se presentan los casos de dos pacientes inmunocomprometidas que luego presentar episodios de rectorragia se diagnostican con colitis por citomegalovirus que exige tratamiento quirúrgico.
\end{abstract}

PALABRAS CLAVE: Citomegalovirus. Infección por citomegalovirus. Paciente inmunocomprometido. Hemorragia digestiva baja.

\begin{abstract}
Cytomegalovirus infection is an uncommon illness that mainly affects immunocompromised subjects being associated with high morbidity and mortality rates. Reactivation or reinfection of the virus causes various symptoms ranging from asymptomatic forms to severe organ-specific complications, such as severe lower gastrointestinal bleeding. Once diagnosed the infection it is important and necessary to establish an adequate treatment with antivirals, with the surgical option for those cases with gastrointestinal complications depending on the patients clinical situation. We report two cases of immunocompromised patients that after presenting rectal bleeding, were diagnosed of cytomegalovirus colitis, requiring urgent surgery.
\end{abstract}

KEY WORDS: Cytomegalovirus. Cytomegalovirus infection. Immunocompromised patient. Lower gastrointestinal bleeding.

\section{Introducción}

La infección del tracto gastrointestinal por citomegalovirus (CMV) es poco frecuente, aunque en los últimos años se ha incrementado su incidencia debido al mayor uso de inmunosupresores, tratamientos quimioterápicos, aumento de la edad poblacional y la prevalencia del virus de inmunodeficiencia humana (VIH). En estos pacientes, las infecciones por este patógeno pueden ocasionar lesiones de órganos concretos con notable morbimortalidad ${ }^{1,2}$. La colitis por CMV se considera la segunda manifestación específica de órgano más frecuente y puede ocasionar complicaciones graves, como la hemorragia digestiva baja masiva.

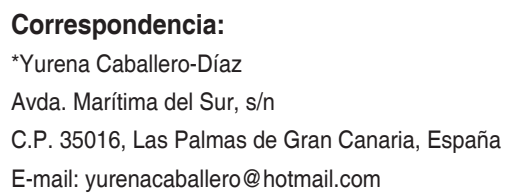

Fecha de recepción: 09-10-2018

Fecha de aceptación: 02-05-2019 DOI: 10.24875/CIRU.19000799
Cir Cir. 2019;Supp 87:688-691 www.cirugiaycirujanos.com 
Se presentan dos casos clínicos de pacientes inmunocomprometidas que sufren hemorragia digestiva masiva secundaria a colitis por CMV.

\section{Presentación de los casos}

\section{Caso 1}

Mujer de 64 años diagnosticada con adenocarcinoma del recto medio (cT2N1a/bM0) en tratamiento neoadyuvante con radioterapia y capecitabina concomitante. Durante el tratamiento manifiesta decaimiento, diarrea con coprocultivo negativo, dolor abdominal y vómitos, por lo que se suspende el quimioterápico. Tras nueva evaluación, la paciente persiste con astenia de grado II-III/IV, enteritis de grado II/IV, sangrado, tenesmo, neutropenia, trombopenia de grado IV/IV e hiponatremia moderada, e ingresa al Servicio de Oncología médica.

Durante su estancia muestra rectorragias con disminución progresiva de la hemoglobina y la colonoscopia revela mucositis tóxica secundaria a la capecitabina; se inicia tratamiento corticoide. En posteriores colonoscopias se observa una mucosa colónica intensamente inflamada, congestiva y friable, con áreas de mucosa indemnes y otras con úlceras de gran tamaño y profundas (Fig. 1A), con biopsia de inflamación aguda y crónica y sin evidencia de neoplasia. Dada la considerable pérdida hemática, la paciente se interviene de manera quirúrgica mediante panproctocolectomía total con ileostomía terminal. La anatomía patológica notifica múltiples úlceras (superficiales y profundas) con presencia de citomegalovirus, probablemente por reactivación del CMV latente (Fig. 2A,B) y signos de peritonitis aguda.

Tras el diagnóstico definitivo se inició tratamiento con valganciclovir a dosis terapéuticas (900 mg/12 h) y se determina la carga viral con reacción en cadena de la polimerasa (PCR) en sangre con el fin de supervisar la respuesta al tratamiento. En la actualidad continúa con tratamiento con disminución de la carga viral determinada mediante PCR.

\section{Caso 2}

Mujer de 54 años con antecedentes de lupus eritematoso sistémico (LES), nefropatía y artropatía lúpica en tratamiento crónico con prednisona (15 mg/día), púrpura trombocitopénica y necrosis avascular de la cabeza del fémur que requirió colocación de prótesis. Ingresa en la Unidad de Cuidados Intensivos por

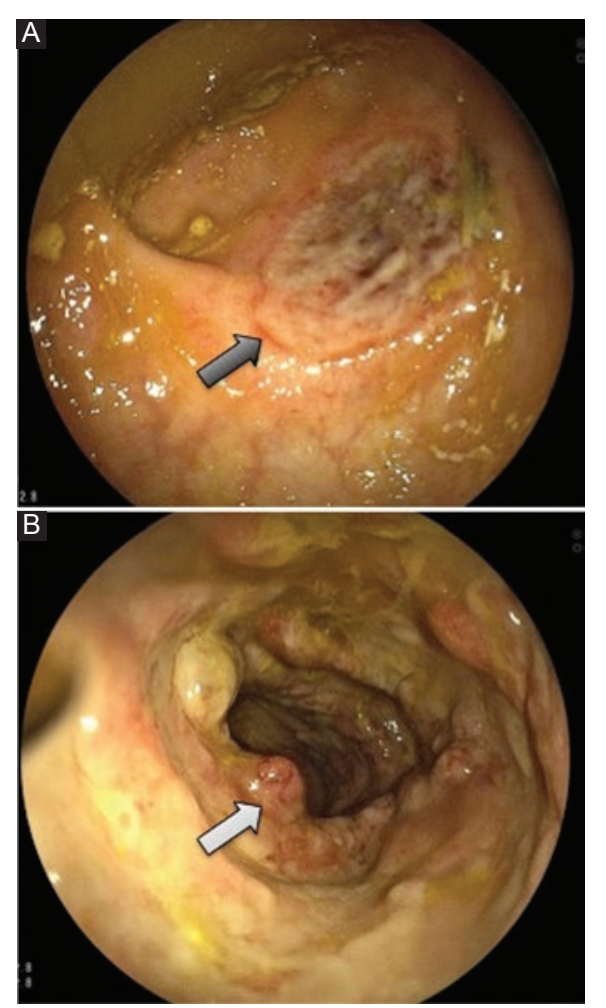

Figura 1. Endoscopia digestiva baje donde se muestra la afectación colónica por citomegalovirus. A: úlcera por CMV. B: pseudopólipo por CMV.

choque séptico de origen osteoarticular que exige drenaje del absceso y remoción de la prótesis izquierda. Durante su ingreso presenta fiebre y diarrea sanguinolenta que requiere transfusión de dos concentrados de eritrocitos. Se practica colonoscopia diagnóstica que delinea múltiples seudopólipos y úlceras irregulares profundas rodeadas de mucosa de aspecto normal en sigma, ángulo esplénico y colon derecho (Fig. 1B).

En virtud de la elevada sospecha clínica de infección por reactivación de CMV, se realiza PCR para determinar la carga viral de CMV (919 UI/ml) con una velocidad de replicación de 1010 copias $/ \mathrm{ml}$ y positividad para anticuerpos IgG e IgM, por lo que recibe tratamiento ganciclovir a dosis terapéuticas. A la semana de tratamiento, la paciente presenta cuadro de rectorragia masiva e inestabilidad hemodinámica que requiere fármacos vasoactivos para su mantenimiento y operación de urgencia (colectomía total y anastomosis ileorrectal).

En la histología definitiva se identifica un área empedrada elevada y ulcerada de $6 \times 4 \mathrm{~cm}$ en ciego y otra de $5.5 \times 3 \mathrm{~cm}$ en el transverso. El perfil inmunohistoquímico detecta positividad para CMV en escasas células, con VHS1, PAS, Giemsa y Warthin Starry negativos, sin observar patógenos (Fig. 2C). 


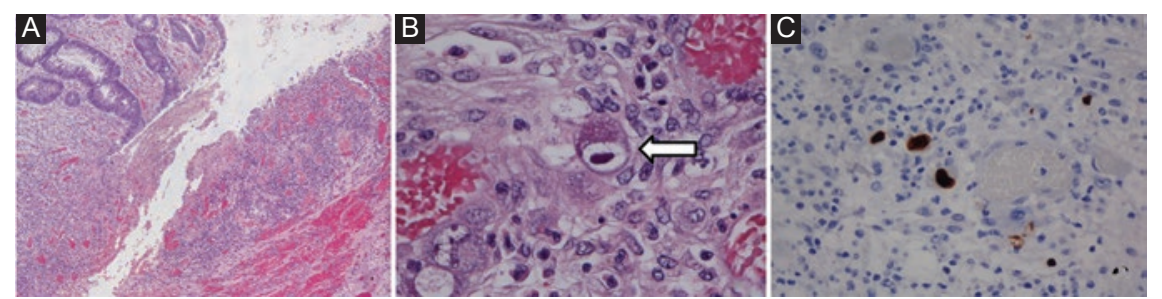

Figura 2. Imágenes histológicas de la colitis por CMV. A: corte histológico de colon con afectación por CMV y tinción con hematoxilina-eosina (x40). Se identifica la formación de glándulas reactivas (a la izquierda de la imagen) y ulceración de la mucosa (a la derecha de la imagen). B: ampliación de la zona de ulceración de la mucosa (x400), donde se observan células con cuerpos de inclusión basófilos que confiere a la célula aspecto de "ojo de búho". C: detección de partículas intracelulares de citomegalovirus por técnicas de inmunohistoquímica.

Luego de 24 horas la paciente experimenta una disminución súbita de la hemoglobina en la analítica, por lo que es reintervenida y revela un hemoperitoneo grave en relación con la coagulopatía de base. A continuación, la paciente muestra mala evolución clínica y sufre un nuevo episodio de hemorragia digestiva baja masiva que no responde al tratamiento médico, por lo que al final fallece.

\section{Discusión}

El CMV es un virus del herpes $\beta$ tipo $V$ presente en el 40 a $90 \%$ de los adultos; se establece como una infección latente después de la resolución de la infección aguda y puede volverse sintomática por su reactivación o por reinfección con una nueva cepa exógena ${ }^{3}$. La reactivación puede ocurrir en cualquier momento durante la vida del huésped y es mayor el riesgo en el contexto de inmunosupresión sistémica relacionada con trasplantes, tratamiento quimioterápi$\mathrm{co}, \mathrm{VIH}$, neoplasias hematológicas, enfermedad inflamatoria intestinal ${ }^{4,5}$, lupus eritematoso sistémico (secundario al tratamiento corticoideo e inmunosupresor $\left.^{6}\right)$ y pacientes críticos. Bajo condiciones de inmunosupresión, el CMV puede causar infecciones sistémicas agudas con replicación en cualquier órgano ${ }^{7}$. Hasta en un $33 \%$ de los pacientes críticos inmunocompetentes seropositivos para CMV se detecta reactivación del CMV determinada por PCR en tiempo real ${ }^{4}$. La diferencia clínica entre una reactivación endógena o reinfección exógena es difícil. Las formas de transmisión son la vía sexual, el contacto estrecho, la exposición a sangre o tejidos contaminados y las exposiciones ocupacional o perinatal.

En huéspedes inmunocompetentes, la infección cursa por lo general de forma asintomática o como una mononucleosis infecciosa; en casos aislados se han descrito enfermedades por CMV con afectación de un solo órgano. Por el contrario, en huéspedes inmunocomprometidos, la infección por CMV puede alcanzar órganos concretos con lesiones y complicaciones graves con una morbimortalidad significativa ${ }^{1,2}$.

Entre las múltiples complicaciones específicas de órgano cabe destacar la afectación gastrointestinal, que puede afectar a la totalidad del tubo digestivo; el colon es el punto más frecuente, seguido por el duodeno, estómago, esófago e intestino delgado ${ }^{8}$. En la mayor parte de los casos, la colitis por CMV ocurre tras la reactivación del CMV en pacientes inmunocomprometidos. La clínica fluctúa entre síntomas inespecíficos como dolor abdominal o diarrea y complicaciones letales como la hemorragia digestiva grave, la perforación intestinal o el megacolon tóxico ${ }^{8}$.

La colonoscopia es la prueba complementaria recomendada cuando existe afectación colónica ${ }^{9}$ y el hallazgo endoscópico más frecuente es la ulceración de la mucosa del colon. La morfología típica es una úlcera grande y pueden observarse un engrosamiento de los pliegues del colon que se difuminan o eliminan el patrón vascular de la mucosa ${ }^{10}$, cambios eritematosos en la mucosa con erosión y, con menor frecuencia, lesiones focales de la mucosa en forma de seudopólipos e incluso perforación.

Existen varios métodos de confirmación diagnóstica de la infección por CMV, entre los que destacan tres en particular. Primero, la determinación de la antigenemia del CMV que detecta los antígenos del CMV sin separación del virus del tejido, y que consiste en detectar las células infectadas mediante el uso de técnicas de inmunofluorescencia y un anticuerpo contra el antígeno temprano y el antígeno pp65 (Ag pp65) del CMV; posee una sensibilidad de 60 a 100\% y una especificidad de 83 a 100\% $\%^{7}$. Segundo, la confirmación histológica, considerada la norma de referencia diagnóstica. Ésta incluye la visualización de cuerpos de inclusión en células epiteliales y endoteliales (célula con aspecto de "ojo de búho")"1. La sensibilidad de la detección de CMV en los tejidos ha mejorado con el uso de tinciones con inmunoperoxidasa o inmunofluorescencia para los antígenos del CMV y utilización de 
anticuerpos monoclonales o hibridación del DNA in situ?. Por último, el diagnóstico del CMV por PCR.

El análisis del DNA-CMV tiene mayor sensibilidad para el diagnóstico y para supervisar la carga viral; sin embargo, puede dar lugar a una baja especificidad. No existe consenso en el método ideal a utilizar.

Los casos presentados son el reflejo de dos espectros posibles de la infección y enfermedad causada por el CMV. Por un lado, una paciente oncológica en tratamiento quimioterápico que desarrolla una clínica gastrointestinal inespecífica que se relaciona con la toxicidad del tratamiento, sin llegar al diagnóstico hasta el estudio histológico de la pieza quirúrgica. Por el otro, una paciente con LES subyacente, que tras un proceso séptico sufre infección por CMV con consecuencias letales. Es de destacar que los pacientes con LES tienen un alto riesgo de infección por $\mathrm{CMV}^{6}$ debido a su tratamiento inmunosupresor. Sin embargo, en algunos casos la presentación clínica se superpone a la del LES y puede pasar inadvertida la infección por CMV. En la bibliografía actual existen pocos casos descritos de colitis por CMV en LES; se han notificado casos de hemorragia gastrointestinal e incluso perforación de colon producida por CMV que requirió intervención quirúrgica urgente ${ }^{12,13}$. Por ello es importante su diagnóstico correcto y diferenciarlo de la vasculitis producida en el LES. Otro aspecto que no debe perderse de vista en ambas pacientes es el tratamiento con corticoides, considerado un factor de alto riesgo de infección por CMV.

Respecto del tratamiento, la primera elección es la terapia antiviral como el ganciclovir o el valganciclovir durante 21 días, aunque la duración depende de la gravedad de la infección. En caso de resistencia o intolerancia al ganciclovir se puede prescribir foscarnet durante dos a tres semanas. Las complicaciones gastrointestinales como hemorragia masiva, megacoIon tóxico, perforación y estenosis requieren tratamiento quirúrgico.

\section{Conclusión}

La colitis por CMV debe considerarse dentro del diagnóstico diferencial de la hemorragia digestiva baja en el paciente inmunodeprimido y crítico. El diagnóstico de confirmación requiere colonoscopia con biopsia que demuestre la presencia del virus en el organismo, con la opción de realizar una determinación por PCR, a la espera del resultado de la biopsia. El tratamiento depende de la gravedad clínica, pero los antivirales son la primera elección.

\section{Financiamiento}

Los autores declaran que no recibieron patrocinio para llevar a cabo este artículo.

\section{Conflicto de intereses}

Los autores declaran que no existe ningún conflicto de intereses.

\section{Responsabilidades éticas}

Protección de personas y animales. Los autores declaran que para esta investigación no se han realizado experimentos en seres humanos ni en animales.

Confidencialidad de los datos. Los autores declaran que han seguido los protocolos de su centro de trabajo sobre la publicación de datos de pacientes.

Derecho a la privacidad y consentimiento informado. Los autores han obtenido el consentimiento informado de los pacientes y/o sujetos referidos en el artículo. Este documento obra en poder del autor de correspondencia.

\section{Bibliografía}

1. Cohen JI, Corey GR. Cytomegalovirus infection in the normal host. Medicine. 1985;64:100.

2. Horwitz CA, Henle W, Henle G, Snover D, Rudnick H, Balfour HH Jr, et al. Clinical and laboratory evaluation of cytomegalovirus-induced mononucleosis in previosuly healthy individuals. Report of 82 cases. Medicine. 1986;65:124.

3. Ross SA, Arora N, Novak Z, Fowler KB, Britt WJ, Boppana SB. Cytomegalovirus reinfections in healthy seroinmune women. J Infect Dis. 2010;201:386.

4. Boeckh M, Geballe AP. Cytomegalovirus: pathogen, paradigm, and puzzle. J Clin Invest. 2011;121:1673-80.

5. Lawlor G, Moss AC. Cytomegalovirus in inflammatory bowel disease: pathogen or innocent bystander? Inflamm Bowel Dis. 2010;16:1620-27.

6. Ramos-Casals M, Cuadrado MJ, Alba P, Sanna G, Brito-Zerón P, Bertolaccini $L$, et al. Acute viral infections in patients with systemic lupus erythematosus. Description of 23 cases and review of the literature. Medicine. 2008;87:311-18.

7. Nakase $\mathrm{H}$, Herfarth $\mathrm{H}$. Cytomegalovirus colitis, cytomegalovirus hepatitis and systemic cytomegalovirus infection: common features and differences. Inflamm Intest Dis. 2016;1:15-23.

8. Binicier OB, Sari SO. Acute fulminant-onset synchronized CMV-ulcerative colitis. Arch Iran Med. 2019;22(2):99-101.

9. Lin WR, Su MY, Hsu CM, Ho YP, Ngan KW, Chiu CT, et al. Clinical and endoscopic features for alimentary tract cytomegalovirus disease: report of 20 cases with gastrointestinal cytomegalovirus disease. Chang Gung Med J. 2005;28:476-84.

10. Chuah SK, Changchien CS, Kuo CM, Wu KL, Chiu KW, Chiu YC, et al. Gastrointestinal tract cytomegalovirus disease in southwestern Taiwan: a clinical study of 1950 endoscopic biopsies. Chang Gung Med J. 2005;28:467-75.

11. Patel SM, Cohen P, Pickering MC, Gazzard BG, Andreyev J. Succesful treatment of acute hemorragic cytomegalovirus colitis with ganciclovir in an individual without overt inmunocompromised. Eur J Gastroenterol Hepatol. 2003;15:1055-60.

12. Ikeda K, Nakajima S, Tanji K, Hirai T, Uomori K, Morimoto S, et al. Intestinal perforation due to hemorrhagic Cytomegalovirus enteritis in a patient with severe uncontrolled lupus nephritis: a case and review of the literature. Rheumatol Int. 2017;37(8):1395-99.

13. Mustafa Dawood, Abubakar Tauseef, Janki Patel.Cytomegalovirus infection in the setting of occult ulcerative colitis: case report and review of the literature. J Community Hosp Intern Med Perspect. 2018;8(6):382-85. 